Travers, M. S., S. Driskill, A. Stemen, T. Geelhoed, D. Golden, S. Koike, A. A. Shipley, H. Moon, T. Anderson, M. Bache, and A. F. Raine. 2021. Post-collision impacts, crippling bias, and environmental bias in a study of Newell's Shearwater and Hawaiian Petrel powerline collisions. Avian Conservation and Ecology 16(1):15. https://doi.org/10.5751/ACE-01841-160115

Copyright (C) 2021 by the author(s). Published here under license by the Resilience Alliance.

Research Paper

\title{
Post-collision impacts, crippling bias, and environmental bias in a study of Newell's Shearwater and Hawaiian Petrel powerline collisions
}

\author{
Marc S. Travers ${ }^{1}$, Scott Driskill ${ }^{1}$, Angela Stemen ${ }^{2,3}$, Theresa Geelhoed $^{2,3}$, David M. Golden ${ }^{2,3}$, Shiho Koike ${ }^{2,3}$, Amy A. Shipley ${ }^{2,3,4}$, \\ Hannah E. Moon ${ }^{5}$, Tracy Anderson ${ }^{3,6}$, Molly Bache ${ }^{3,6}$ and Andre F. Raine ${ }^{1}$ \\ ${ }^{1}$ Archipelago Research and Conservation, ${ }^{2}$ Kauai Endangered Seabird Recovery Project, Pacific Cooperative Studies Unit, \\ University of Hawaii, ${ }^{3}$ State of Hawaii Division of Forest and Wildlife, ${ }^{4}$ University of Wisconsin-Madison, ${ }^{5}$ Department of \\ Biology, University of Hawai'i at Mānoa, Honolulu, HI , ${ }^{6}$ Save Our Shearwaters, Kauai Humane Society
}

\begin{abstract}
Powerline collisions have been identified on Kaua'i as a potential contributing factor to the large-scale decline of both Hawaiian Petrel (Pterodroma sandwichensis) and Newell's Shearwater (Puffinus newelli), but the scale of the powerline collision problem is unknown. From 2012 to 2020 we conducted observations for seabird powerline collisions across Kaua'i, documented grounded seabirds, and assessed crippling and environmental biases - both poorly studied facets of powerline collision research. We directly observed 121 powerline collisions and detected 89 grounded seabirds. While some collisions resulted in birds falling lifelessly out of the sky, most resulted in seabirds flying or gliding outside of the search area. This means that traditional ground searches would underestimate total collisions by $78-88 \%$ if not accounting for crippling bias. We tested environmental bias by comparing our ability to conduct searches for grounded birds, "searchability", across multiple variables. Environmental bias resulted in significant reductions in searchability across regions, environment types, and powerline heights. Furthermore, observed collision rates were significantly higher at powerlines that had very low to zero searchability. Forty-three percent of observed collisions occurred at unsearchable powerlines (mainly spanning steep valleys), equating to an estimated 3170 seabird collisions that could not be detected through ground searches. We detected powerline collisions in every region of Kaua'i, in every environment type, and at all powerline heights monitored. Our results show that crippling bias and environmental bias are the mechanisms that concealed the geographic distribution of collisions and the scale of the powerline problem from grounded bird searches, ultimately preventing the detection of thousands of collisions. The data collected for this study are critical for assessing the scale of seabird powerline collisions and quantifying the biases inherent in traditional ground searches.
\end{abstract}

\section{Collisions de Puffins de Newell et de Pétrels des Hawaï avec les lignes électriques : impacts post- collision, biais inhérent aux blessures et à l'environnement}

RÉSUMÉ. Les collisions avec les lignes électriques sur Kaua'i ont été identifiées comme facteur contribuant potentiellement à la baisse à grande échelle du Pétrel des Hawaï (Pterodroma sandwichensis) et du Puffin de Newell (Puffinus newelli), mais l'ampleur de ce problème est inconnue. De 2012 à 2020, nous avons été témoins de collisions d'oiseaux marins avec des lignes électriques sur Kaua'i, documenté les oiseaux marins trouvés au sol et évalué les biais inhérents aux blessures et à l'environnement - deux facettes peu étudiées dans les études sur les collisions avec les lignes électriques. Nous avons assisté à 121 collisions avec des lignes électriques et détecté 89 oiseaux marins morts au sol. Si certaines collisions ont été fatales sur le coup pour les oiseaux marins, la plupart des oiseaux ont continué à voler ou à planer en dehors de la zone de recherche. Ce résultat indique que les recherches traditionnelles d'oiseaux morts au sol sousestimeraient le nombre de collisions de 78 à $88 \%$ si l'on ne tenait pas compte du biais inhérent aux blessures. Nous avons testé le biais environnemental en comparant notre capacité à effectuer des recherches d'oiseaux au sol, la « facilité de recherche», selon de nombreuses variables. Le biais environnemental s'est traduit par des réductions importantes de la facilité de recherche dans toutes les régions, les types d'environnement et la hauteur des lignes électriques. De plus, les taux de collisions observés étaient beaucoup plus élevés sur les lignes électriques dont la facilité de recherche était très faible ou nulle. Quarante-trois pourcent des collisions observées se sont produites avec des lignes électriques pour lesquelles il était impossible de faire des recherches au sol, ces lignes traversant surtout des vallées abruptes, ce qui équivaut à 3170 collisions d'oiseaux marins environ qui n'ont pas pu être détectées au moyen de recherches au sol. Nous avons détecté des collisions avec les lignes électriques dans toutes les régions de Kaua'i, dans tous les types d'environnement et à toutes les hauteurs de lignes électriques inventoriées. Nos résultats montrent que le biais inhérent aux blessures et le biais environnemental sont les mécanismes qui ont faussé la répartition géographique des collisions et l'ampleur du problème des lignes électriques étudiée à partir de recherches d'oiseaux au sol, empêchant ultimement de détecter des milliers de collisions. Les données récoltées dans le cadre de cette étude sont essentielles pour évaluer l'ampleur des collisions entre les oiseaux marins et les lignes électriques et quantifier les biais inhérents aux recherches traditionnelles au sol.

Key Words: Carcass search; Crippling bias; Environmental bias; Grounded bird searches; Hawaiian Petrel; Newell's Shearwater; Powerline collision; Powerline height; Seabirds 


\section{INTRODUCTION}

Since seabird population trend monitoring began in 1993 on Kaua'i Hawaii, the Hawaiian Petrel (Pterodroma sandwichensis; 'Ua'u in Hawaiian) and Newell's Shearwater (Puffinus neweilli; 'Ao' in Hawaiian) have declined by 78 and $94 \%$ respectively (Raine et al. 2017). Determining the causes of the decline is a critical conservation goal for these endangered Hawaiian endemics. This is particularly important because the majority of the world's remaining Newell's Shearwater population breeds on this single island (Cooper and Day 1998, Pyle and Pyle 2017, Ainley et al. 2019) along with significant breeding populations of the Hawaiian Petrel population (Cooper and Day 1998, Pyle and Pyle 2017).

Powerline collisions have been identified as one of the top anthropogenic causes of avian mortality, killing tens of millions of birds annually in North America alone (Loss et al. 2014, 2015, Rioux et al. 2013). On Kaua'i, powerlines collisions were identified as a potential contributing factor to seabird decline (Ainley et al. 2001, Raine et al. 2017). A 1993-1994 study observing the behavior of seabirds crossing powerlines on Kaua' $i$ identified a high-powerline collision risk (Cooper and Day 1998). Nine percent of seabirds (Newell's Shearwaters and Hawaiian Petrels) crossing powerlines came within $1 \mathrm{~m}$ of colliding with the powerlines, and $19 \%$ and $30 \%$ of observed Newell's Shearwaters and Hawaiian Petrels came within $5 \mathrm{~m}$ of hitting the lines, respectively. Also in 1993 and 1994, separate grounded bird search studies showed that powerline collisions were a significant source of sub-adult and breeding adult Newell's Shearwater mortality (Cooper and Day 1998, Podolsky et al. 1998) and grounded bird data was subsequently used to estimate the overall impact of powerlines on Newell's Shearwaters (Podolsky et al. 1998).

While determining the impact of powerlines on birds is most commonly assessed through grounded bird searches this can lead to an underestimation of collisions if common biases are not addressed (Jenkins et al. 2010, Rioux et al. 2013, Bernardino et al. 2018, Barrientos et al. 2018). Grounded birds can be missed by searchers or removed by scavengers prior to the search and therefore it is common to report the searcher detection rate and carcass removal rates within the designated search corridor around powerlines (Jenkins et al. 2010, Barrientos et al. 2018). However, although it is clear that crippling bias and environmental bias can lead to significant undercounting of powerline collisions (Bevanger 1995, 1998, Saverno et al. 1996, Rioux et al. 2013, Loss et al. 2014, Murphy et al. 2016) they are rarely quantified in the literature because of the effort required to determine the scale of these biases (Rioux et al. 2013, Bernardino et al. 2018, Barrientos et al. 2018).

Crippling bias occurs when birds that hit powerlines fly or glide outside of the grounded bird search corridor, and thus the collision cannot be detected through a ground search. Crippling bias can result in a $65-75 \%$ undercounting of powerline collisions (Saverno et al. 1996, Murphy et al. 2016). Under-counting of powerline collisions can also occur in grounded bird search studies through environmental bias when powerlines exist in varied environments that differ in their searchability (Bevanger 1995, Loss et al. 2014, Barrientos et al. 2018). Environmental bias is likely an important issue to address on Kaua'i, as grounded bird searches conducted at low elevation powerlines are often facilitated by the open terrain of roads with cleared road shoulders next to the powerlines. However, powerlines transiting the interior of the island which are constructed across steep valleys, ridges, and over tropical vegetation are functionally unsearchable. Previous powerline collision monitoring on Kaua'i did not quantify crippling bias or environmental bias, and most of the interior powerlines (which in some cases transit directly through breeding habitat) were not monitored at all (Day and Cooper 1995, Cooper and Day 1998, Podolsky et al. 1998, Ainley et al. 2001).

The impact of powerline collisions on the Newell's Shearwaters and Hawaiian Petrels of Kaua'i needs to be reevaluated considering the dramatic population declines both species have experienced since the early 1990's. We conducted a 9-year study to observe seabird powerline collisions across Kaua'i, as well as collecting grounded seabirds throughout the study period. We present data on the first directly observed endangered seabird powerline collisions and collision outcomes ever recorded in Hawaii. We consider crippling bias by quantifying the proportion of seabirds that fly or glide beyond the search corridor along with post-collision flight characteristics as a proxy for injury severity. We consider environmental searchability bias across the powerline geographic regions and assess the number of seabird powerline collisions that have been concealed from search studies because they are occurring in unsearchable terrain. Lastly, we report on the geographical distribution of detected powerline collisions across the powerline grid on the island, as well as collisions relative to powerline construction type, height, and light pollution. The results of this study will be critical in understanding how and to what extent traditional grounded bird searches underestimate powerline collisions, as well as assessing the range of powerline constructions and habitats that pose a powerline collision risk to seabirds.

\section{METHODS}

\section{Visual detection of collisions}

Newell's Shearwaters and Hawaiian Petrels transit between the sea and breeding colonies at dusk and throughout the night (Day and Cooper 1995, Raine et al. 2017). To facilitate detection of nocturnal collisions and observe post-collision impacts, we used night vision goggles (Model PVS-7m Generation 3, $40^{\circ}$ field of view, 1x magnification, U.S. Night Vision, Roseville, California, USA) in combination with near-infrared illuminators (NIRI, Raymax-300-Platinum 50-180'; Raytec, Ashigton, Northumberland, UK). The NIRI greatly enhanced the capabilities of night vision and facilitated better visual tracking of individual seabirds preand post-collision. NIRI were not used in 2012, and for logistical reason were used only at low elevation sites in 2013. From 2014 onward NIRI were used for all observations. In 2012 and 2013, prior to full utilization of NIRI to enhance night vision, observers used a thermal camera (Flir E60, with lens options of 10, 16, $30 \mathrm{~mm}$ ) in select remote high elevation locations with low ambient light levels.

When conducting the surveys, observers were positioned to monitor the wires between two power poles with their field of view oriented from the first pole to the second pole, ensuring that powerlines were always in their view. All collisions reported here were detected near to or following astronomical twilight (i.e., full 
darkness), requiring the optical equipment described above. The overlapping breeding season of both the Newell's Shearwater and Hawaiian Petrel begins with the very earliest returning Newell's Shearwaters arriving in late March and the departure of the last Hawaiian Petrels occurring in late December (Andre Raine personal communication). The fledgling period begins at the very end of September and ends in December. Visual monitoring for seabird collisions predominantly occurred ( $97 \%$ of effort) from the beginning of May to the end of September.

\section{Crippling bias}

Crippling bias is defined as the proportion of birds that collide with powerlines but that manage to fly or glide beyond the search corridor before dying (Loss et al. 2014, Bernardino et al. 2018). Quantifying crippling bias cannot be accomplished through traditional ground searches and requires a tagging study that tracks birds post-collision to determine short and long-term mortality (Bevanger 1995). Tagging sufficient numbers of birds that then collide with powerlines is a major logistical challenge and, as such, has not been conducted to date (Bernardino et al. 2018, Barrientos et al. 2018). Therefore, in practical terms, crippling bias has been reported as the proportion of birds observed hitting powerlines that then fly or glide outside of the search corridor (Saverno et al. 1996, Rioux et al. 2013, Murphy et al. 2016) without the ability to track survival. In an attempt to reduce confusion, we use the term "max crippling bias" in this paper for birds that were observed hitting the powerlines and then flew, glided, or crawled outside of the search corridor, because these birds actually represent the upper possible bound for the true crippling rate. It is unlikely that all birds classified as max crippling bias would die. For this reason, we report post-collision impacts on flight as a proxy for injury severity and likelihood of crippling (i.e., mortality) among the "max crippling bias" birds to better approximate the true rate of crippling. We also report grounded seabirds outside of the search corridor to confirm that some of the birds that collide with the lines and leave the search area are in fact grounded quickly.

\section{Post-collision impacts on flight}

For all observed seabird collisions, we collected data on 1) observed elevation loss, 2) description of post-collision flight characteristics, and 3) the immediate collision outcome- i.e., max crippling bias, immediately grounded or unknown outcome.

We calculated observed elevation change, which is the change in the bird's height in the sky following the collision. To enable accurate estimate of elevation change, observers compared the bird's change in height post-collision relative to an object in their field of view, which we refer to as a scaler. We pre-measured the height of the scaler (with Laser Range Finder and Lidar, see details below), which was most often a power pole or the space between powerlines. To quantify post-collision elevation change, the observer reported the bird's elevation change as a fraction or multiple of the scaler (e.g., -1.2 power poles) which was then converted to meters of elevation loss. We report observed elevation loss rather than total elevation loss because the tracking of falling birds post-collision was often impacted by obstructions such as vegetation. In areas where powerlines cross valleys, we tracked falling birds for up to 80 meters below the wires. However, in our most constrained observation areas (i.e., those areas with trees or bushes positioned below the wires or between the observers and the wires) observers could only track falling birds for several meters below the powerlines before they disappeared from view.

Observations of seabird flight post-collision were collated into 5 characteristic descriptions ranging from the most severe category of "no flight" to the least severe "powered flight". The most serious category of "no flight" described a post-collision seabird that did not regain any flight control because they were falling limp/lifeless, cartwheeling/tumbling, or parachuting down (bird was alert and dropping with wings open but had no forward flight speed). "Seriously compromised flight" included seabirds that had large and sustained elevation loss ( $>20$ meters) towards a hazard (i.e., ground, cliff, or trees) that clearly demonstrated limited flight control. For example, the flight of birds in this category was at best described as only able to generate enough lift for a steeply angled descent. "Compromised flight" described birds that had elevation loss combined with less severe but visibly altered flight (e.g., gliding more than typical, altered flight path from original/typical path, flight path for a hazard). "Powered flight" described birds that maintained or gained elevation postcollision even if the collision initially caused them to lose elevation through cartwheeling or tumbling. Lastly the category "inconclusive" described birds that could not clearly be assigned to either compromised flight or powered flight.

Observed collision outcomes included "max crippling bias", "immediately grounded", and "unknown outcome". We defined collisions resulting in the outcome category of "max crippling bias" as those birds that flew, glided, or crawled beyond our 60meter search corridor (30 meters of either side of wires) and "immediately grounded" as those birds observed descending within the search corridor. The terrain and vegetation where observations were carried out often made it almost impossible to directly see the exact moment when an immediately grounded seabird contacted the ground. To estimate immediate grounding, we therefore considered a combination of elevation loss, postcollision flight characteristics, and distance to location-specific hazards on the bird's trajectory. We classified a bird as immediately grounded only if the above information clearly indicated that a bird would have been grounded in the search corridor (e.g., birds falling lifelessly or angling sharply towards the ground). Lastly, a subset of the collisions were labeled as "outcome unknown" where birds were observed descending until they were lost from view with insufficient distance $(<20$ meters $)$ to definitively determine an outcome.

\section{Grounded seabirds}

Grounded seabird detections are reported to provide data on visible injuries, powerline sections with confirmed collisions, grounded bird distance from wires relative to our standardized search corridor, and to compare the geographic distribution relative to the searchability of powerlines and the distribution of observed collisions. In this paper we report after hatch year (AHY) grounded Newell's Shearwater and Hawaiian Petrels (i.e., both subadults and breeding adults). We do not report hatch year (HY) grounded seabirds in this study, because HY birds (fledglings) are most often grounded due to light attraction or collisions that result from light attraction. We differentiated between AHY and HY birds based on plumage wear and sun fading, with grounded fledglings only being present during the 
fledging period from late September-through December. Most grounded seabirds were detected opportunistically by seabird biologists while driving (i.e., not during standardized surveys) and occasionally while hiking near powerlines. Members of the public also reported grounded birds, predominantly live birds, to the local rehabilitation program called Save Our Shearwaters (SOS). At all grounded bird locations distance to the powerlines was determined using either a laser range finder or comparing a GPS point collected at the grounding location to powerline locations using ArcGIS. All birds were carefully examined for any visible sign of injury.

\section{Environmental bias and powerline searchability}

Environmental bias is an under-estimation of grounded birds due to dangerously steep terrain, thick vegetation, or other logistical constraints preventing ground searches (Bevanger 1995, Loss et al. 2014, Barrientos et al. 2018). We used the term environmental bias rather than habitat bias because in the context of seabirds transiting past powerlines the search corridor footprint around powerlines is unrelated to land use by the seabird (i.e., habitat). We assessed the prevalence of unsearchable powerline sections and compared searchability across powerline regions (defined below). If environmental bias is present on Kaua'i this would prevent studies relying on ground searching from determining the true geographic distribution of seabird powerline collisions. We report the searchability of powerlines across regions, environments, and powerline heights and we report if observed collisions occur in non-searchable areas. We also compared the distribution of observed seabird collisions, collision rates, and total estimated collisions with that of grounded seabirds to determine if studies relying solely on ground searching would underestimate collisions.

To quantify environmental bias through searchability, we delineated a search corridor around all powerlines studied and determined the searchability of each discrete section of powerlines (i.e., the length of wires between two power poles). We set the search corridor to 60 meters total width ( 30 meters either side of wires) following Saverno et al. (1996). We defined a section of the corridor as "searchable" if searchers could physically enter and feasibly search the area to conduct a search and "unsearchable" if it was too dangerous to search (i.e., steep mountainous terrain), if vegetation completely inhibited walking, or if we were restricted from entering (private property restrictions are common on Kaua'i).

Specifically, we measured the accessible area (i.e., "searchable" terrain) relative to the total length and width of the search corridor around all powerlines (i.e., total search corridor area). Most of the searchable terrain at powerlines is clearly mapped by publicly available tax maps, state, and county maps (geodata. hawaii.gov 2020) which delineate the accessible areas that are provided by public lands, roads, and road right of way (e.g., road shoulders). These maps also clearly show the boundaries with private land which would prevent searches. We used Arc GIS tools to quantify the proportion of the powerline search corridor that overlapped with the publicly searchable terrain. This initial layer was then manually edited for accuracy using in-depth local knowledge, and additional areas of searchability along roads, on private lands, or along wilderness trails were delineated using a digital surface model or Google Earth imagery. The resulting layer of searchable areas is used to summarize searchability at each powerline section with detected collisions and across all powerline regions.

\section{Observed collision rates and estimated collision numbers}

We compared observed collision rates across corridor searchability to test the impacts of environmental bias. When conducting surveys, we recorded the length of powerlines being observed and the time monitored. The section of powerlines observed was most typically the space between two sequential power poles (i.e., a discrete powerline section) and each sections' length was measured using high-resolution lidar. From 2012 to 2020 , we conducted multiple surveys at a total of 416 unique powerline sections. We observed 50,488 meters of powerlines which amounts to $23.4 \%$ of the $216 \mathrm{~km}$ of powerlines we monitored for collision risk. We generally monitored the portion of night following sunset and prior to sunrise for a total of 4.01 \pm 0.64 hours per night similar to Cooper and Day (1998). Our total observation effort was 6,484 hours or $16 \pm 45$ hours per individual observed wire section. We report the rates as collisions per 100 meters of powerline per hour.

We report estimated collision numbers to determine if environmental searchability bias is leading to underestimation of total collisions. We estimated collision numbers, $\mathrm{CN}$, with the following formula:

$$
\mathrm{CN}=\mathrm{CR} * \mathrm{~L} * \mathrm{NH} * \mathrm{NY} * \mathrm{Y}
$$

We first determined the site-specific collision rate, $\mathrm{CR}$, as observed collisions per meter per hour. We measured the length, $\mathrm{L}$, of each monitored powerline section using high resolution lidar. We quantified the mean site-specific hours each section was monitored per night, $\mathrm{NH}$, to determine the length of the night with the observed collision rate. We used the number of nights between May 1 and September 30, as the nights per year that collision risk exists, NY. Lastly, we summed the number of years involved in the present study, Y.

We restricted the estimation of collision numbers to only the time periods of the night and year in which we collected the data for the baseline collision rates. We used a night length $(\mathrm{NH})$ specific to the number of hours we monitored each powerline section per night $($ mean $=4.01 \pm 0.64$ hours). We did not extend the estimation to include the full night (mean $=10.96 \pm 0.44$ hours) because collision rates likely differ in the portion of the night we did not monitor. We used a collision season length (NY) of 152 nights (May 1-September 30), despite confirming with the detection of grounded seabirds that powerline collisions also occur in April, October, and November. We did not extend the estimation to include the full confirmed collision season because collision rates likely differ in the portion of the season we did not monitor intensely. This conservative approach does not impact the comparison of collision numbers across corridor searchability for the purposes of understanding the impacts of environmental bias.

\section{Powerlines and regions}

We present confirmed collision (observed collisions and or grounded seabirds) by powerline regions across Kaua'i, for the 
Fig. 1. Kaua'i powerline regions and powerline corridor searchability

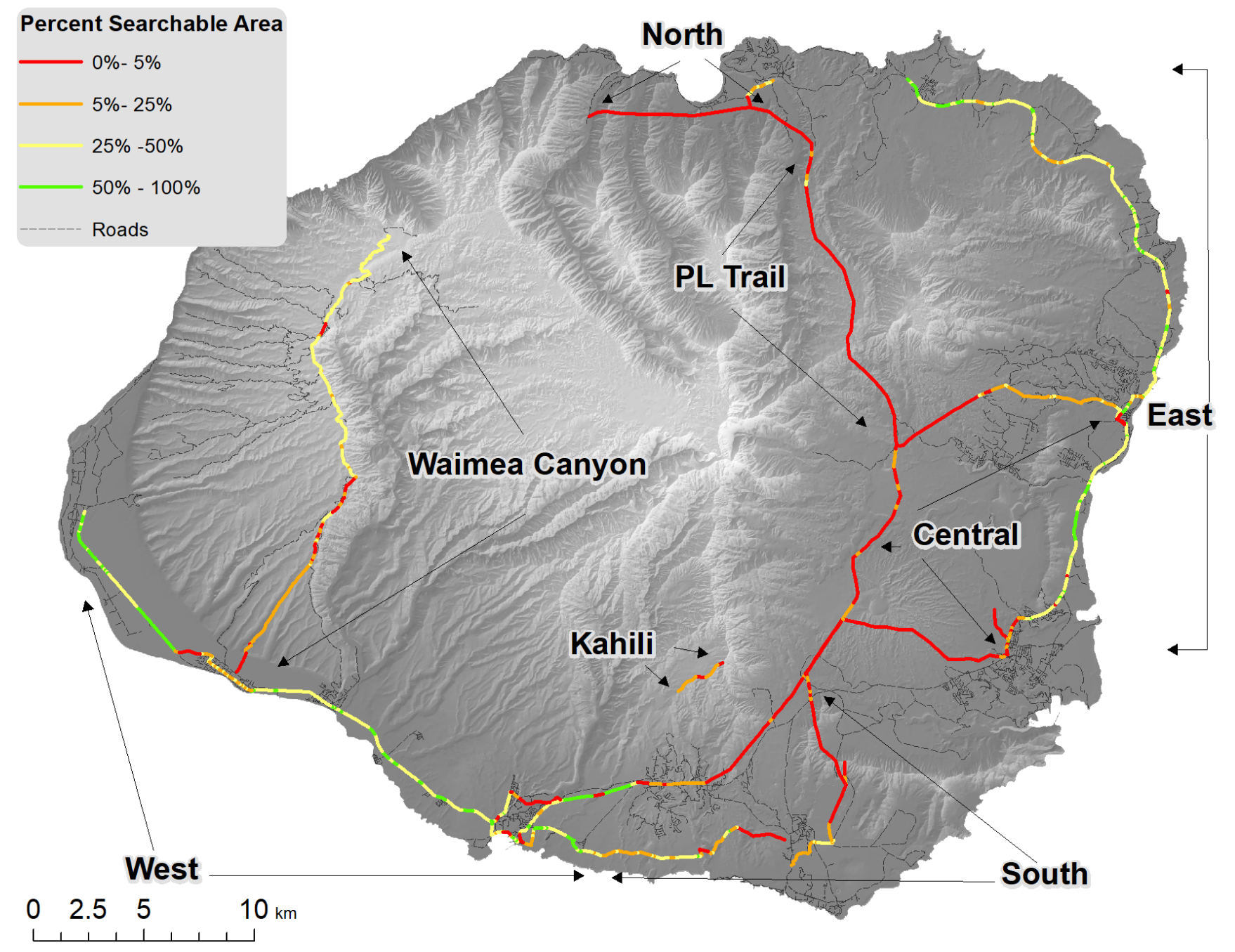

purposes of documenting their geographical distribution and the associated powerline height, and we present light pollution levels at confirmed collision locations. We demarcated Kaua'i's powerlines into regions (Fig. 1) by grouping powerlines with similar construction types (wire number and height) within similar island regions (east, west, south, north) and environments (low elevation, inland, high elevation, etc.). Observations occurred at a subset of powerlines within all Kaua'i's high voltage transmission powerline regions which consist of $186.2 \mathrm{~km}$ of powerlines. Observations were also conducted at a subset of low voltage distribution lines $(30.4 \mathrm{~km}$ that are constructed in higher risk areas such as along high elevation ridgelines and through seabird colonies). These sections of distribution wires are referred to as Waimea Canyon and Kahili in figures and tables. From an avian collision perspective, the most salient difference between powerline construction types is that high voltage powerlines are constructed with taller power poles (i.e., wires are mounted higher above ground) and the individual wires are spaced further apart compared with the lower voltage distribution powerlines. The powerlines we considered encircle much of Kaua'i, including most of the remaining suitable endangered seabird breeding habitat (Troy et al. 2014, 2017). The one region without powerlines is the north-western portion of Kauai, including the uninhabited $\mathrm{Na}$ Pali coast region. Powerline heights and section lengths were derived from aerial lidar data with a vertical accuracy of 15 centimeters root mean square error and a point density of 15 points per square meter. Light pollution is often a variable of interest in studies of seabird groundings. For this reason, we obtained the mean annual light pollution levels for the years 2012-2020 from the website https://eogdata.mines.edu/products/ $\mathrm{vnl} /$ for each section of powerlines in radiances (units $=\mathrm{nW} / \mathrm{cm}^{2}$ / sr). This annual mean light pollution dataset was developed by Elvidge et al. (2021) from the NASA/NOAA Visible Infrared Imaging Radiometer Suite (VIIRS). We used the annual data to produce a mean light pollution level across all years of the study.

\section{Data filtering and statistics}

13 seabird collisions were observed while using a thermal camera or night vision goggles without the assistance of NIR 
Table 1. Post-collision flight characteristics and elevation loss.

\begin{tabular}{|c|c|c|c|c|c|c|}
\hline $\begin{array}{l}\text { Severity } \\
\text { rank } \\
(\mathrm{SR})\end{array}$ & $\begin{array}{l}\text { Post Collision flight } \\
\text { characteristics }\end{array}$ & $\begin{array}{l}\text { Observed } \\
\text { seabird } \\
\text { collisions }\end{array}$ & $\begin{array}{l}\text { Percent of } \\
\text { total } \\
\text { collisions }\end{array}$ & $\begin{array}{c}\text { Observed } \\
\text { Elevation loss } \\
\text { meters } \\
(\text { Mean } \pm \mathrm{SD})\end{array}$ & $\begin{array}{c}\text { Observed } \\
\text { Elevation loss } \\
\text { meters (min, max) }\end{array}$ & $\begin{array}{c}\text { Wilcox test } \\
\text { Pairwise } \\
\text { comparisons }\end{array}$ \\
\hline 1 & No flight & 16 & 14.8 & $36 \pm 21$ & 10,70 & A \\
\hline 2 & Seriously compromised flight & 8 & 7.4 & $36 \pm 24$ & 20,80 & $\mathrm{~A}, \mathrm{~B}$ \\
\hline 3 & Compromised flight & 7 & 6.5 & $14 \pm 4$ & 10,20 & $\mathrm{~A}, \mathrm{~B}$ \\
\hline 4 & Inconclusive & 4 & 3.7 & $6 \pm 5$ & 1,10 & B \\
\hline \multirow[t]{2}{*}{5} & Powered flight & 73 & 67.6 & $3 \pm 5$ & 0,20 & $\mathrm{C}$ \\
\hline & Total \& Means & 108 & 100 & $11 \pm 17$ & 0,80 & \\
\hline
\end{tabular}

illumination. We removed these observations from any analyses requiring elevation loss or a detailed description of post-collision flight characteristics because the observation equipment limited our ability to track the bird's flight outcome after the collision. These 13 collisions observed with lower quality equipment were however used when reporting total observed collisions and when reporting powerline regions, powerline heights, and searchability at powerlines that had observed collisions. Grounded seabirds reported by the public were excluded from this paper if accurate location information was not provided.

To confirm that our classifications of post-collision seabird flight patterns are associated with differences in changes of flight height, we conducted a non-parametric Kruskal-Wallis test. We used a Wilcoxon rank sum test for pair-wise comparisons. The same tests were used in the same manner for elevation change related to the post-collision outcome categories and comparing searchability at grounded bird locations versus observed collision locations. We used a Wilcoxon rank sum test for comparisons of collision rates across two searchability categories of "low" and "high" searchability which we defined as $<8 \%$ and $>8 \%$ corridor searchability, respectively. This delineation was based on a gap in the range of searchability at powerline sections with observed collisions. That is, observed collisions were not evenly distributed across the range of searchability from $0-100 \%$, with collision clusters observed across a range of low searchability powerlines ( $<8 \%$ searchable) and two clusters at higher searchability powerlines $(>8 \%=$ clusters at $\sim 50 \%$ and $100 \%$ searchable $)$. Spearman rank correlations were used to test for relationships between searchability and the following metrics; above-ground height of powerlines (mean top wire height), steepness of terrain (slope), and the proximity of powerlines in meters to suitable breeding habitat as identified by Troy et al. $(2014,2017)$ who provided the GIS layers of suitable breeding habitat. A Spearman rank correlation was used to test for a relationship between light pollution levels and the observed collision rates. Statistics were conducted using $\mathrm{R}$ statistical software version 3.6.1 (R Core Team, 2019). Means are reported as \pm the standard deviation and p-value of $<0.05$ was considered significant.

\section{RESULTS}

\section{Total observed seabird powerline collisions}

We observed 121 endangered seabird powerline collisions between 2012 and 2020 (Fig. 2). The species ratio was 29.5\% $(\mathrm{n}=26 / 88)$
Hawaiian Petrels to 70.5\% $(n=62 / 88)$ Newell's Shearwaters. The remaining 33 observations were identified as either Hawaiian Petrels or Newell's Shearwaters based on flight characteristics and size but could not be identified between the two species. These birds are referred to as unidentified endangered Procellariformes or UNPE. Observed collisions were detected in each of the months from May through September, with no collisions observed during the fledgling period. 108 of the 121 seabird collisions were observed with observation equipment that allowed for elevation loss tracking and improved post-collision outcome determination.

\section{Elevation loss}

Overall, mean elevation loss post-collision was $11 \pm 17$ meters ( $\mathrm{n}$ $=108)$, which includes a subset $(46.7 \%)$ of birds that did not lose any elevation. When examining just the $53.3 \%$ of birds that did lose elevation, the mean observed elevation loss was $18 \pm 19$ meters with a minimum and maximum of 1 and 80 meters.

\section{Post-collision flight characteristics}

Post-collision, $14.8 \%$ of seabirds did not regain flight (i.e., "no flight" classification) within the observer's field of view (Table 1). $7.4 \%$ did not regain controlled flight (i.e., "seriously compromised flight" classification). $6.5 \%$ of seabirds regained some flight control ("compromised flight" classification).

$67.6 \%$ of seabirds were able to regain (e.g., after tumbling) or maintain "powered flight" after the collision. Lastly, 3.7\% had inconclusive post-collision flight characteristics. There was significantly more elevation loss in the 3 most severe post-collision flight classifications compared to the lest severe (Kruskal-Wallis $\mathrm{X}^{2}=65.177, \mathrm{df}=4, \mathrm{p}<0.0001$, Table 1).

\section{Immediate short-term collision outcome \& max crippling bias}

Of the 108 observed seabird collisions considered, 13.0\% were immediately grounded. Immediately grounded birds had the largest observed elevation losses (50 \pm 17 meters) and all were observed with the 2 most severe post-collision flight classifications (Table 2 and Fig. 3). One of the 14 immediately grounded birds was observed dropping only 15 meters and was alert and parachuting down but was confirmed on the ground (33 meters below wire) by an immediate search.

$10.2 \%$ of collisions resulted in unknown outcomes. The mean elevation loss in this category was $17 \pm 6$ meters and birds were 
Fig. 2. Distribution of observed powerline collisions and grounded seabirds. The suitable breeding habitat is presented to highlight the inland areas of breeding habitat that transiting seabirds necessarily head towards and away from when transiting past powerlines. The suitable breeding habitat data was reproduced with permission from Troy et al. (2014) and Troy et al. (2017).
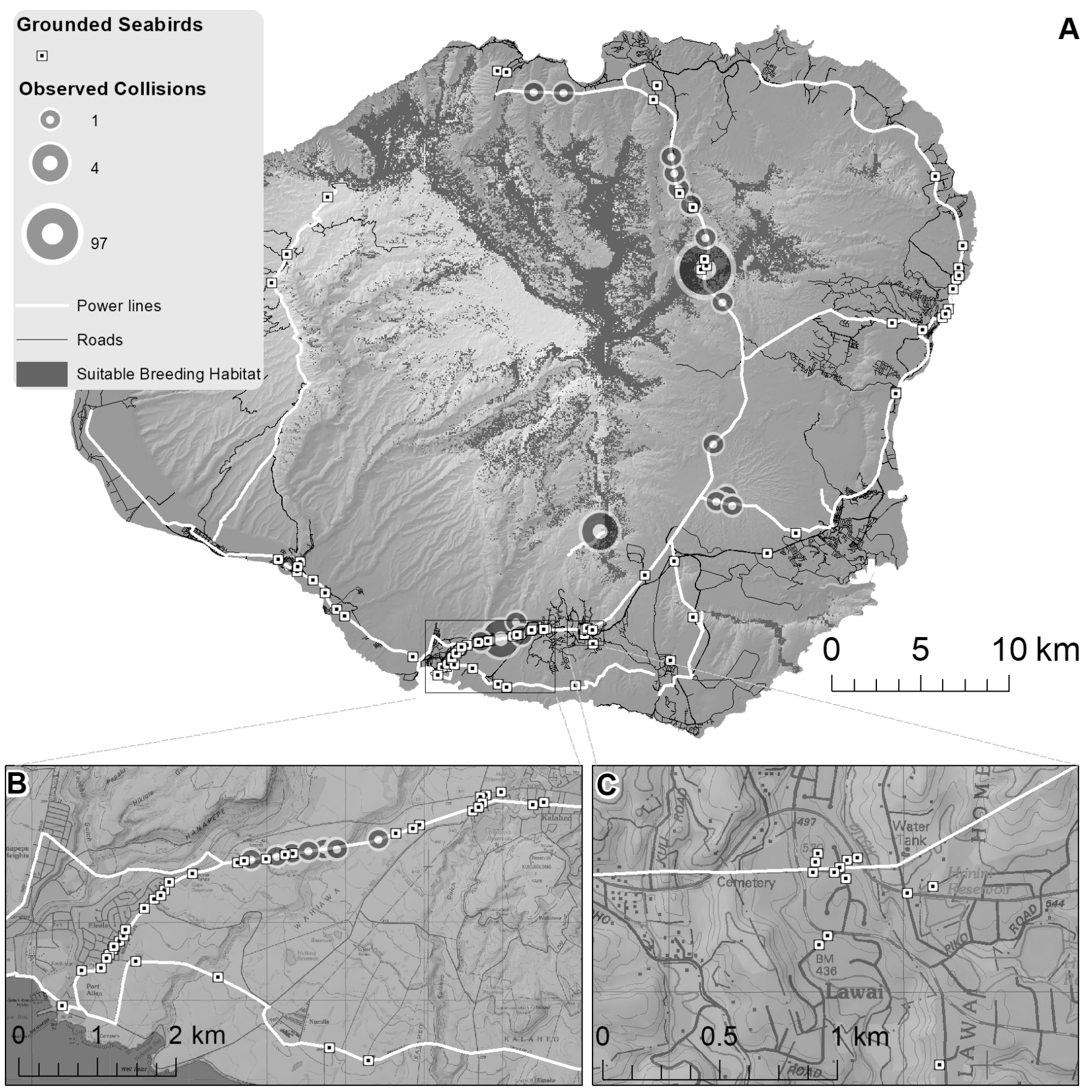

observed with the 3 most severe post-collision flight classifications (Table 2 and Fig. 3).

$76.9 \%(n=83 / 108)$ were categorized as max crippling bias because these birds were observed flying or gliding outside of the search corridor after the collision $(\mathrm{n}=81 / 108)$ or no bird was detected in post-collision searches (described below), confirming the birds had left the search corridor $(n=2 / 108)$. Most max crippling bias birds were observed in the least severe post-collision flight classification. The mean elevation loss was $3 \pm 5$ meters. When comparing across all categories, elevation loss significantly varied by outcome (Kruskal-Wallis $\mathrm{X}^{2}=55.994, \mathrm{df}=2, \mathrm{p}<0.0001$, all pairwise comparisons $\mathrm{p}<0.001$, Table 2 and Fig. 3). Two max crippling bias birds that were classified as "no flight" collided with 
Table 2. Post-collision flight characteristics by collision outcome categories.

\begin{tabular}{|c|c|c|c|c|c|c|}
\hline Outcome Category & No flight & $\begin{array}{c}\text { Seriously } \\
\text { compromised } \\
\text { flight }\end{array}$ & $\begin{array}{l}\text { Compromised } \\
\text { flight }\end{array}$ & Inconclusive & Powered flight & Totals \\
\hline Immediately Grounded & $\begin{array}{c}10.2 \% \\
(11)\end{array}$ & $\begin{array}{c}2.8 \% \\
(3)\end{array}$ & $\begin{array}{l}0 \% \\
(0)\end{array}$ & $\begin{array}{l}0 \% \\
(0)\end{array}$ & $\begin{array}{l}0 \% \\
(0)\end{array}$ & $\begin{array}{c}13.0 \% \\
(14)\end{array}$ \\
\hline Unknown Outcome & $\begin{array}{l}2.8 \% \\
(3)\end{array}$ & $\begin{array}{c}4.6 \% \\
(5)\end{array}$ & $\begin{array}{c}2.8 \% \\
(3)\end{array}$ & $\begin{array}{l}0 \% \\
(0)\end{array}$ & $\begin{array}{l}0 \% \\
(0)\end{array}$ & $\begin{array}{c}10.2 \% \\
(11)\end{array}$ \\
\hline Crippling Bias & $\begin{array}{c}1.9 \% \\
(2)\end{array}$ & $\begin{array}{l}0 \% \\
(0)\end{array}$ & $\begin{array}{c}3.7 \% \\
(4)\end{array}$ & $\begin{array}{c}3.7 \% \\
(4)\end{array}$ & $\begin{array}{c}67.6 \% \\
(73)\end{array}$ & $\begin{array}{c}76.9 \% \\
(83)\end{array}$ \\
\hline Totals & $\begin{array}{c}14.8 \% \\
(16)\end{array}$ & $\begin{array}{c}7.4 \% \\
(8)\end{array}$ & $\begin{array}{c}6.5 \% \\
(7)\end{array}$ & $\begin{array}{c}3.7 \% \\
(4)\end{array}$ & $\begin{array}{c}67.6 \% \\
(73)\end{array}$ & $\begin{array}{l}100 \% \\
(108)\end{array}$ \\
\hline
\end{tabular}

wires in a $100 \%$ searchable area and were not found on the subsequent search initiated immediately following the collision. It is possible the birds recovered flight as they were observed dropping 10 and 15 meters leaving 23-18 meters of airspace below the observer's field of view or they were grounded but immediately crawled out of the search corridor into a thick stand of coffee bushes.

Fig. 3. Observed elevation loss by post-collision outcome category. Letters represent results of non-parametric pair-wise comparisons.

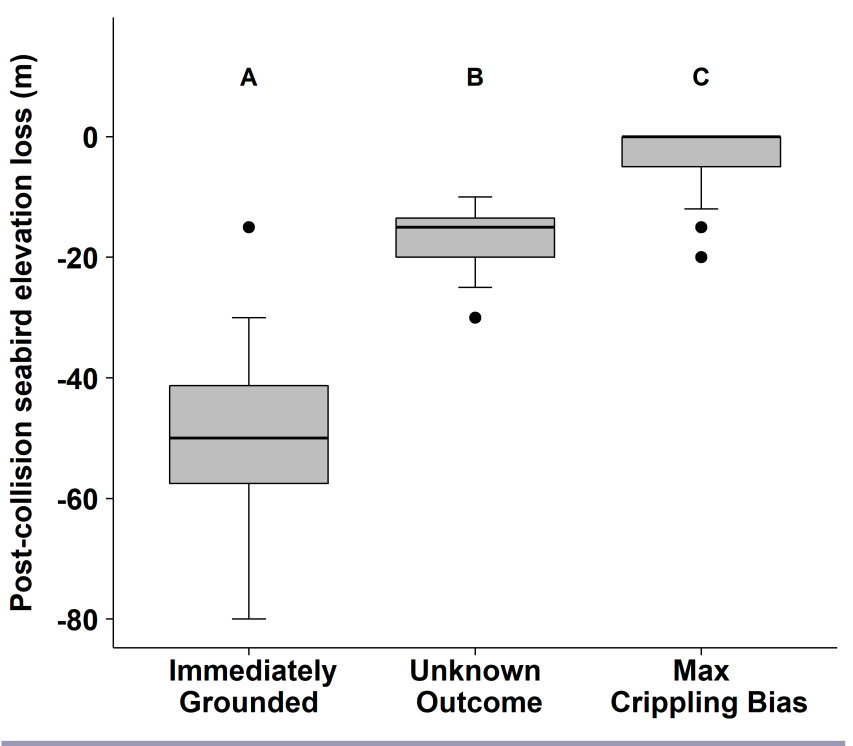

One Newell's Shearwater was both immediately grounded and secondarily left the search corridor increasing the max crippling bias to $77.8 \%(n=84 / 108)$. This seabird was observed hitting a powerline which caused it to cartwheel down into a second wire, after which it continued cartwheeling downwards for another 5 meters until it righted itself and parachuted down (i.e., bird was conscious and in control of orientation but did not have any forward flight speed) into coffee bushes for a total drop of 33 meters. Once on the ground the bird reversed its orientation and headed directly back in the direction of the ocean by wing-bashing the ground (failed attempt at flight) and moving quickly across the ground. The bird was unable to regain flight despite immediately entering a farm road 17 meters wide and 202 meters long, with a steady breeze blowing down the length of the road. The bird was secondarily classified in the max crippling bias category because it was exiting the search transect when it was intercepted and collected by the observer.

\section{Grounded seabirds}

89 grounded endangered seabirds were detected during the study period (Fig. 2). We detected AHY birds in each month from April through November, with peak detections occurring in May, June, August, and September and the fewest grounded birds detected in April, July, October, and November (Fig. 4). No grounded birds were detected in March or December.

Fig. 4. Grounded seabird detections by month.

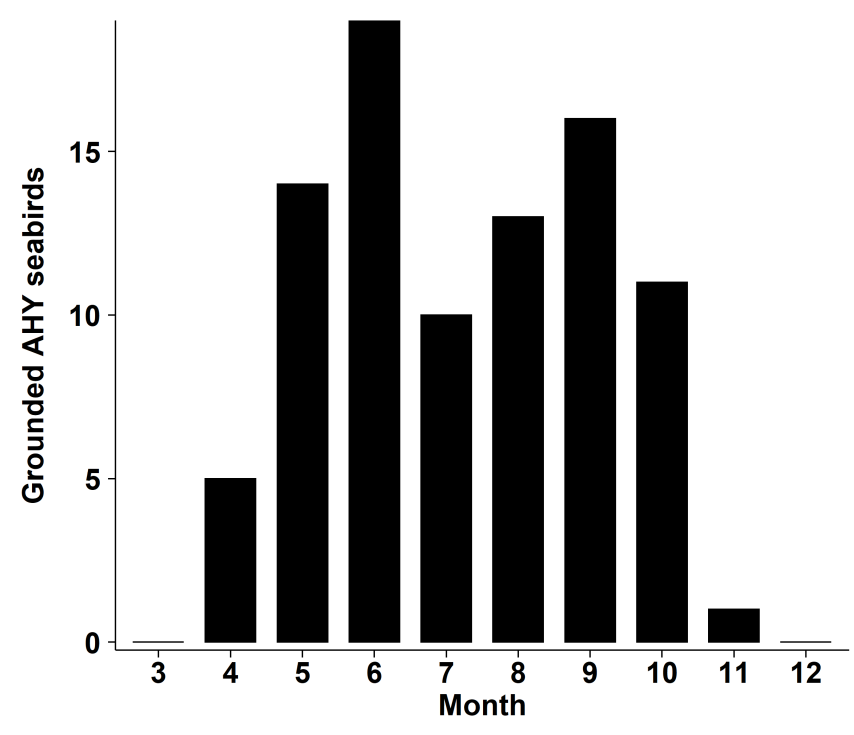

The species ratio was $12.4 \%$ Hawaiian Petrels to $87.6 \%$ Newell's Shearwaters. At the time of detection, $69.7 \%$ of grounded seabirds were found dead and $30.3 \%$ alive. Several seabirds which were found alive later succumbed to their injuries at the rehabilitation center, increasing mortality to $83.1 \%$. The remaining $16.9 \%$ successfully flew out to sea only after the intervention and or 
Table 3. Regional searchability, powerline collision numbers, and wire heights at collision sites.

\begin{tabular}{|c|c|c|c|c|c|c|c|}
\hline Region & $\begin{array}{l}\text { Length of } \\
\text { powerlines } \\
\text { (m) }\end{array}$ & $\begin{array}{c}\text { Regional } \\
\text { searchability } \\
(\%) \\
\text { Mean } \pm \text { SD }\end{array}$ & $\begin{array}{c}\text { Grounded } \\
\text { Seabirds }\end{array}$ & $\begin{array}{c}\text { Observed } \\
\text { seabird } \\
\text { powerline } \\
\text { collisions }\end{array}$ & $\begin{array}{l}\text { Top powerline } \\
\text { height }(\mathrm{m}) \text { at } \\
\text { collision sites } \\
\text { Mean } \pm \text { SD }\end{array}$ & $\begin{array}{l}\text { Top powerline } \\
\text { height }(\mathrm{m}) \text { at } \\
\text { collision sites } \\
\text { Min, max }\end{array}$ & $\begin{array}{c}\text { Environment } \\
\text { types at } \\
\text { collision sites }\end{array}$ \\
\hline $\begin{array}{l}\text { Waimea } \\
\text { Canyon }\end{array}$ & 26,992 & $21 \pm 13$ & 3 & 0 & $12 \pm 3$ & 9,14 & $\begin{array}{l}\text { High elevation } \\
\text { ridgeline }\end{array}$ \\
\hline Kahili & 3,366 & $8 \pm 5$ & 0 & 4 & $15 \pm 2$ & 14,16 & $\begin{array}{c}\text { Mid elevation } \\
\text { mountain } \\
\text { ridgeline }\end{array}$ \\
\hline East & 41,954 & $37 \pm 17$ & 11 & 0 & $17 \pm 3$ & 15,25 & $\begin{array}{c}\text { Low elevation } \\
\text { coastal }\end{array}$ \\
\hline West & 51,147 & $40 \pm 21$ & 41 & 8 & $24 \pm 6$ & 15,33 & $\begin{array}{l}\text { Low elevation } \\
\text { coastal, } \\
\text { residential, \& } \\
\text { agricultural }\end{array}$ \\
\hline South & 26,494 & $15 \pm 15$ & 20 & 0 & $31 \pm 9$ & 19,45 & $\begin{array}{l}\text { Low elevation } \\
\text { valley \& } \\
\text { residential }\end{array}$ \\
\hline Central & 38,890 & $6 \pm 10$ & 5 & 4 & $37 \pm 8$ & 28,47 & $\begin{array}{l}\text { Low elevation } \\
\text { rolling hill, } \\
\text { valley, \& } \\
\text { agricultural }\end{array}$ \\
\hline PL Trail & 15,131 & $2 \pm 5$ & 5 & 103 & $37 \pm 16$ & 24,70 & $\begin{array}{l}\text { Mid elevation } \\
\text { mountain } \\
\text { valley, ridge, } \\
\text { inland plateau }\end{array}$ \\
\hline North & 12,561 & $9 \pm 14$ & 4 & 2 & $43 \pm 6$ & 39,53 & $\begin{array}{c}\text { Inland ridge } \& \\
\text { valley }\end{array}$ \\
\hline
\end{tabular}

medical rehabilitation provided by the Save Our Shearwaters Rehabilitation Program.

Only $56.2 \%(n=50)$ of grounded seabirds were detected in a condition that allowed for an injury assessment. Of these, $20.0 \%$ had no detectable injuries when live $(n=5)$ or dead $(n=5) .2$ live birds without visible injuries displayed behaviors symptomatic of a neurological injury and later died while in rehabilitation. $10.0 \%$ of seabirds had detectable wing injuries which displayed as compound humerus fractures $(n=2)$, elbow injuries $(n=2)$, and a wrist injury $(n=1) .70 .0 \%$ of grounded seabirds had visible injuries to the head area, which displayed as injuries to the bill including fractures and bifurcation $(n=9)$, eye injuries $(n=5)$, and feather removal on forehead, crown, check, or neck $(n=21)$. Blood was commonly found in the nares and mouth of dead seabirds. The head injuries on dead seabirds ranged in severity from a bird with a hole in its forehead and a bird with a destroyed eye to visually minimal injuries such as small patches of feathers missing.

Grounded seabirds were detected within the search corridor $70.8 \%$ of the time with median distances from the wires of 9 meters $(\mathrm{n}=63$, mean $\pm \mathrm{sd}=10 \pm 8, \min =0, \max =28)$ and outside of the standardized search corridor $29.2 \%$ of the time with median distances from wires of 138 meters $(n=26$, mean $\pm \mathrm{sd}=292 \pm 351$, $\min =31, \max =1120)$. Considering all birds, the median distance from powerlines was 15 meters (mean $\pm \mathrm{sd}=97 \pm 232$ ).
The Lawai Valley on the south side of the island (Fig. 2 inset C) was considered further as this is the grounding hotspot with the most extended searchability on Kaua' $i$ in the form of roads and residences from 0-300 meters and again from 500-900 meters from powerlines. In the Lawai Valley $69 \%$ of seabirds were detected beyond the standardized search corridor. Considering all birds within and beyond the search corridor, the median distance from powerlines in Lawai was 40 meters $(n=13$, mean $\pm s d=146 \pm 238$, $\min =2, \max =868$ ).

\section{Environmental bias}

There was clear evidence of environmental bias as searchability varied significantly across powerline regions (Kruskal-Wallis $\mathrm{X}^{2}$ $=673.91, \mathrm{df}=7, \mathrm{p}<0.001$ ), from a mean of $1.7 \%$ searchable within the Powerline Trail region corridor to a mean of $39.6 \%$ searchable in the Western powerline regions' corridor (Fig. 1 and Table 3). Corridor searchability was correlated with potential seabird powerline collision risk factors. We found that searchability was significantly lower at powerlines constructed closer to suitable seabird breeding habitats $\left(\mathrm{r}_{\mathrm{s}}=0.29, \mathrm{P}<0.001\right)$ in steeper terrain $\left(r_{s}=-0.33, P<0.001\right)$ and was significantly lower at taller powerlines $\left(r_{s}=-0.22, P<0.001\right) .67$ percent of the island's tallest powerline sections (above the $90^{\text {th }}$ percentile wire height) could not be searched at all.

Overall searchability was largely explained by the proximity of powerlines to public roads. The 60 -meter-wide search corridor 
around all powerlines resulted in a total potential search area of $12,388 \mathrm{~km}^{2}$. Overall searchability within the corridor was $20 \%$ $\left(2,474 \mathrm{~km}^{2}\right)$. Most of the searchable area was public access roads and road shoulders $\left(2,215 \mathrm{~km}^{2}\right)$, followed by special access roads and agricultural fields $\left(247 \mathrm{~km}^{2}\right)$, and then public hiking trails (12 $\left.\mathrm{km}^{2}\right) .80 \%\left(9,914 \mathrm{~km}^{2}\right)$ of the 60 -meter-wide search corridor was not searchable (no access for searching) due to environmental challenges (dangerously steep and or heavily vegetated terrain) as well as prohibited private land access.

\section{Searchability at powerlines with confirmed collisions, collision rates, and collision numbers}

We observed $43 \%$ of the endangered seabird collisions at powerlines that were unsearchable. The median searchability at observed collision sites was $1.6 \%$ with a larger mean and variance due to a cluster of collisions observed at $100 \%$ searchable powerlines (the 121 collisions occurred at 22 unique powerline sections, $\mathrm{n}=22$, mean searchability $\pm \mathrm{sd}=26 \% \pm 42, \min =0 \%$, $\max =100 \%$ ). Observer monitoring effort does not explain the above pattern as we found no relationship between observation effort in minutes/meter of powerline and the searchability of those powerlines $(n=416$, spearman rho $=0.0014, p=0.98)$.

The highest collision rates were observed at the least searchable powerlines $(n=416$, Wilcoxon Rank Sum $W=19706, p<0.001$, Fig. 5). Powerlines with "low" searchability had a mean collision rate of $0.0023 \pm 0.0072$ per $100 \mathrm{~m}$ per hour, a rate that is 11.5 times the collision rate of $0.0002 \pm 0.0014$ per $100 \mathrm{~m}$ per hour observed at powerlines sections with "high" searchability. $94.7 \%$ of all powerline sections monitored had an observed collision rate of zero. Using these rates, we estimated that there were 6,513 collisions at the monitored powerlines with a non-zero collision rate. 3,170 of these collisions were estimated to occur at powerlines with $0 \%$ searchability (Fig. 6). 1,893 and 971 collisions were estimated at powerlines with searchability between $0-2 \%$ and $2-8 \%$ respectively. 479 collisions were estimated at all powerlines with searchability greater than $8 \%$.

Fig. 5. Observed seabird powerline collision rates at powerline sections with low $(<8 \%)$ and high searchability $(>8 \%)$.

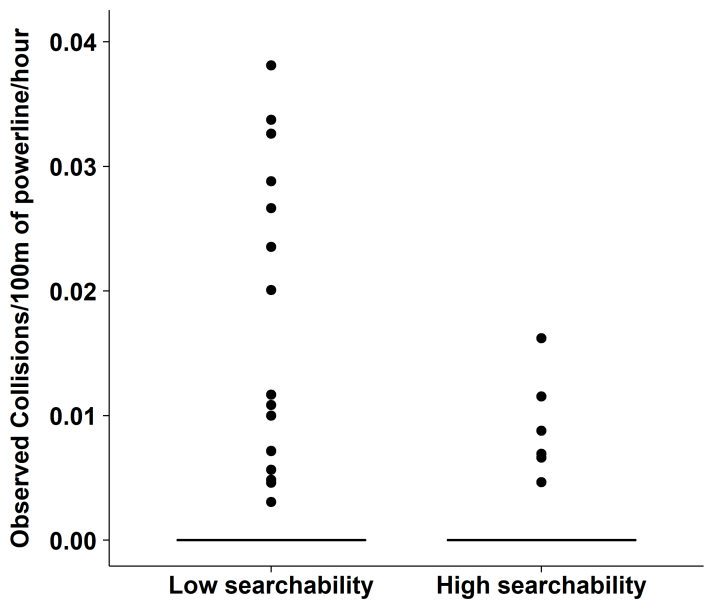

Fig. 6. Estimated seabird collision numbers at powerlines with a non-zero observed collision rate.

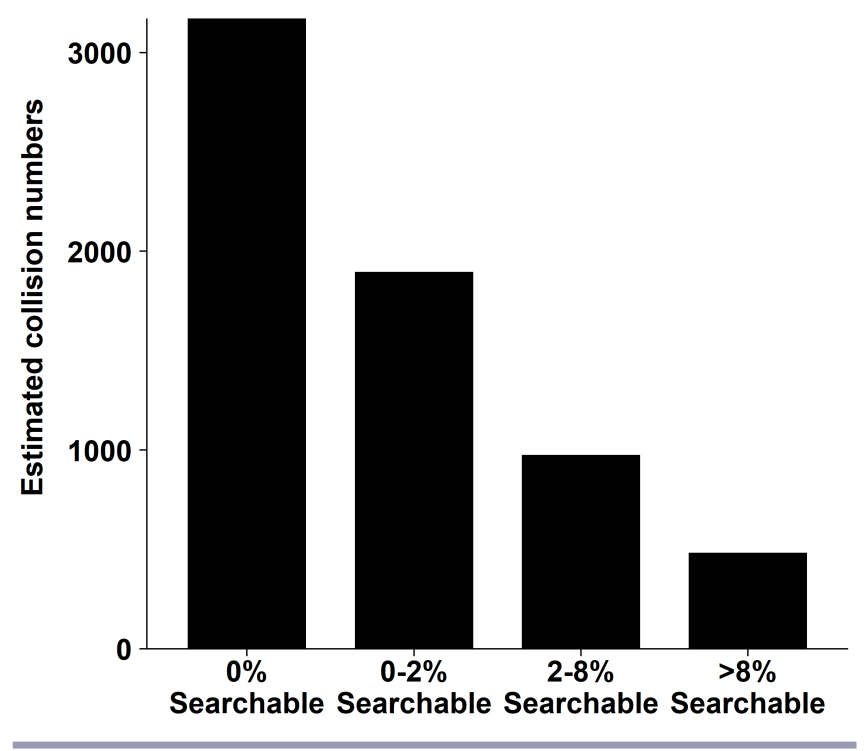

The grounded seabirds were detected at powerlines with a wide range of searchability. Median powerline searchability for birds found within the standardized search corridor was 38\% (the 62 grounded birds occurred at 44 unique powerline sections, $n=44$, mean searchability $\pm \mathrm{sd}=37 \% \pm 28, \min =0.55 \%, \max =100 \%$, see Table 3 ) and $24 \%$ for birds found outside of the search corridor (the 27 grounded birds occurred at 16 unique powerline sections, $\mathrm{n}=16$, mean $\pm \mathrm{sd}=26 \% \pm 23, \min =0 \%, \max =75 \%$ ). Powerline searchability was significantly higher at powerlines with grounded seabirds compared to powerlines with observed collisions (Kruskal-Wallis $\mathrm{X}^{2}=17.962$, df $=2, \mathrm{p}<0.001$, Fig. 7).

Fig. 7. Corridor searchability at powerlines with observed collisions and or grounded seabirds. Presented are medians \pm standard deviation. Letters represent results of non-parametric pair-wise comparisons.

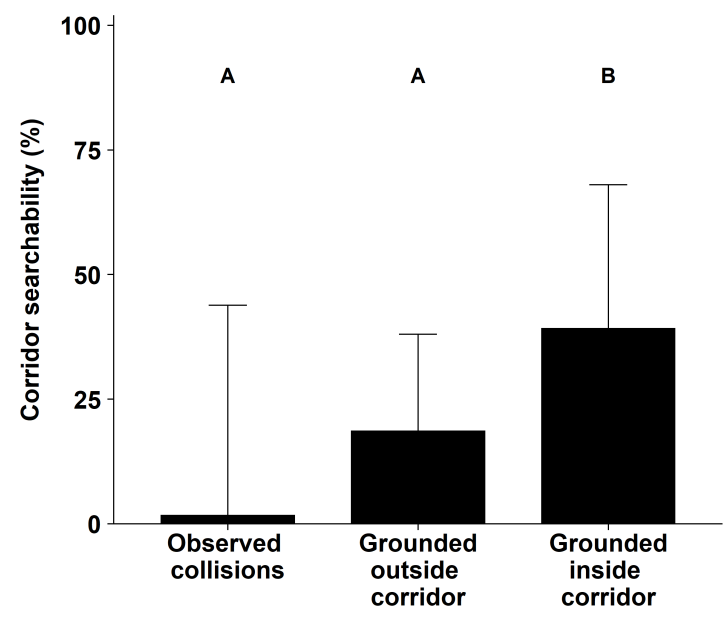




\section{Powerline heights and environment type at collision locations}

Seabird powerline collisions (observed and/or grounded seabirds) were documented at powerlines which had mean top wire heights that ranged from 9 to 70 meters above ground (210 collisions occurred at 86 unique locations $n=86$, median $=24$ meters, mean $\pm \mathrm{sd}=27 \pm 11$; see Table 3 for Regional means). Powerline collisions were confirmed in all powerline regions ranging numerically from 3 to 108 documented collisions per region. Collisions were not confined to specific landscape features such as valleys and river mouths. Collisions were confirmed at powerlines located in a wide range of environments including coastal, inland low-elevation, mid-elevation, high-elevations, in residential areas, on ridges, over valleys, on mountain plateaus, hilly terrain, flat agricultural areas, and in forested areas where trees are shorter than powerlines.

Confirmed collisions occurred most often in areas with relatively low light pollution with the median radiance at collision locations being $0.41 \mathrm{nW} / \mathrm{cm}^{2} / \mathrm{sr}(\mathrm{n}=86$, mean $\pm \mathrm{sd}=1.11 \pm 1.34$, range $=$ $0.11-5.07 \mathrm{nW} / \mathrm{cm}^{2} / \mathrm{sr}$ ) which for scale was the $5^{\text {th }}$ percentile considering the range of existing radiances at all powerlines. Furthermore, observed collision rates were negatively correlated with light pollution $(n=416$, spearman rho $=-0.15, p=0.002)$.

\section{DISCUSSION}

Our results confirmed that both the Newell's Shearwater and the Hawaiian Petrel collide with powerlines on the island of Kaua'i. To our knowledge, the direct observation of powerline collisions and the reporting of post-collision impacts is novel for Hawaiian seabirds and seabirds in general. Previous observational research in the 1990's (Cooper and Day 1998) observed numerous near misses with powerlines for both Newell's Shearwaters and Hawaiian Petrels, which suggested collision risk existed, however, there was no visual confirmation of a direct collision for these species.

Increased observation effort allowed the present study to confirm collisions visually, but our 6000 hours of observation effort was still a small fraction of the time period when collisions could occur and will have resulted in an overestimation of the number of powerline sections with a collision rate of zero (i.e., zero inflation). Like Cooper and Day (1998), we too have observed many near misses at powerline sections that currently have a collision rate of zero, which includes observations of high-risk flights of seabirds flying directly between the wires. Similarly, like Cooper and Day (1998) we detected grounded seabirds at powerline sections that currently have a collision rate of zero based on the observed collision data. In the present study, it required 130 hours of nocturnal monitoring ( $\sim 30$ nights given our survey lengths) to establish the lowest collision rate we reported of 0.0031 collisions per $100 \mathrm{~m}$ per hour. Collision rates that are so low they are difficult to detect visually, can sum to large totals at the landscape scale. The lowest detected collision rate resulted in a site-specific estimate of 20.1 collisions per kilometer from May to September. This may appear insignificant until we consider that at the landscape scale there are 216 kilometers of powerlines and we have now confirmed that seabird powerline collisions are occurring in every region and environment type studied.

In the 1990's, a search study conducted simultaneously with the above-mentioned observation study, detected grounded Newell's
Shearwaters but not grounded Hawaiian Petrels (Cooper and Day 1998). Additionally, a separate search study reported grounded Newell's Shearwaters but no Hawaiian Petrels (Podolsky et al. 1998). Without documentation of Hawaiian Petrel collisions, visually or from ground searches, the studies conducted in the early 1990's could be incorrectly interpreted to indicate that powerlines do not pose a risk to Hawaiian Petrels. In the present study, all but one of our Hawaiian Petrel collisions were documented within powerline regions not monitored in the 1990's. That is, most Hawaiian Petrel collisions were documented at remote sites in the interior of the island, in steeper, ridge and valley terrain that were classified as unsearchable, indicating that even the most extensive and thorough search study would not have been able to sufficiently monitor powerline collisions for this species. Likewise, the highest collision rates for Newell's Shearwaters were also detected at the interior unsearchable powerlines. The research from Kauai indicates that the logistical challenges of studying powerline collisions at the landscape level can lead to an overestimate of powerline sections with a collision rate of zero (i.e., zero inflation). As we discuss further, our results show that crippling bias and environmental bias are the mechanisms that concealed the geographic distribution of collisions and the scale of the powerline problem, ultimately preventing the detection of thousands of collisions.

Murphy et al. (2016) reported that Sandhill Cranes Antigone canadensis colliding with powerlines at night had a crippling bias of $65 \%$ and Severno et al. (1996) reported a crippling bias of $71-75 \%$ when pooling together smaller numbers of diurnal collisions across a range of species including gulls, wading birds, shorebirds, terns and a raptor. In this paper we have extended crippling bias data to two Procellarid seabirds, reporting a max crippling bias of $78 \%$ to $88 \%$. All three observation studies show that detected birds in traditional ground searches represent a fraction of total powerline collisions.

Our observations cannot directly quantify the true crippling rate (i.e., long-term survival) of the birds observed flying, gliding or crawling out of the search corridor, which we termed max crippling bias, without a concurrent tagging study (Bevanger 1995). However, our results confirmed that a proportion of the max crippled birds are grounded quickly resulting in true crippling (i.e., mortality), as 31-69\% of grounded seabirds were opportunistically detected beyond the standardized search corridor. We know from flight speeds, that these seabirds were grounded shortly after leaving the search corridor as the slowest a seabird would typically transit the max grounded bird distance of 1100 meters is 82 seconds based on radar flight speed (Day and Cooper 1995, Raine et al. 2017). We suggest that an injury that can cause a bird to become grounded this quickly likely resulted in altered flight immediately following the collision. Moreover, it is reasonable to assume that post-collision flight characteristics and the elevation loss we reported are a reliable indicator of the force of the collision and the vulnerability of the body part directly impacted. Seabirds in each of the three most severe post-collision flight classifications we reported all had clear visibly altered flight immediately following the collision combined with elevation losses. Our results would therefore indicate that the most probable total short-term grounding rate (i.e., within 1100 meters of powerlines) would be $28.8 \%$, which is the sum of the $13.0 \%$ immediately grounded birds, $10.2 \%$ unknown outcome (either immediately grounded or crippled), and 5.6\% of the birds, 
that while observed leaving the search corridor (max crippling bias), had the more severe post-collision flights. We should also consider that even if the bird's flight is not immediately impacted by the collision and quickly grounded, mortality can occur at sea due to unseen traumas (Raine et al. 2020) or even from the removal of feathers which can cause mortality at sea by reducing water proofing (Weimerskirch et al. 2019).

The inverse of the crippling rate is the immediate grounding rate. Murphy et al. (2016) reported that Sandhill Cranes have an immediate grounding rate of $35 \%$ compared to our minimum and maximum (when including unknown outcome collisions with the 3 most severe post-collision flight) immediate grounding rate of $13.0-23.2 \%$. The difference between studies is likely indicative that birds with a lengthened body plan like the Sandhill Crane have an increased risk of catastrophic injuries (see Bevanger 1998, Janss 2000 for injury and collision risk based on morphology). Consistent with past research on Newell's Shearwaters (Cooper and Day 1998), the seabird injuries we reported indicate that collisions impacting the head are by far the most common cause of grounding with wing injuries also causing grounding but to a considerably lesser extent. The collisions we observed reinforce the injury data. The most severe outcomes we observed resulted from head-on collisions, which are most common in the dark locations (no moon visible and no ambient light pollution) where birds are the least likely to detect the powerlines. These birds were often observed falling limp or tumbling with no sign of consciousness or visible attempt to regain flight. Collisions involving the wing from the wrist to the body caused the seabirds to cartwheel with some seabirds recovering flight and some not, while collisions involving the wing distal to the wrist caused minimal impacts on flight. Collisions involving the keel or belly caused a range of impacts from seabirds completely stopping all forward movement or tumbling, with birds usually maintain the ability to flap even if altered, to birds skipping off the wire and continuing at a similar pace and elevation.

During several of the collisions, predominantly in dark locations where wires are most difficult to detect, we observed that the seabirds detected the wires a fraction of a second before colliding, which was too late to avoid the collision altogether. However, the seabirds initiated a flare (Newell's Shearwater and Hawaiian petrel) or a stall (Hawaiian Petrel only) which moved the most vulnerable body parts, such as the bill, head, neck, and sometimes the humerus up and away from direct collision. This shifts the collision impact to more robust body parts such as the keel or belly or body parts that naturally bend in the direction of the collision force such as the wingtips beyond the wrist. This suggests that any modification of the wires that increases detection distance, such as the use of bird diverters (Janss and Ferrer 1997, Barrientos et al. 2011, Ferrer et al. 2020), UV light (Dwyer et al. 2019), or even painting the wires a more visible color, would firstly reduce collisions, but may also reduce the severity of injuries for any remaining collisions.

A minority of the grounded birds were found alive. Some of these birds died during rehabilitation with one known major cause being neurological issues (i.e., unseen head or neck injuries). Some of the birds were successfully returned to the sea after receiving professional care at the Save Our Shearwaters rehabilitation center. It is important to note that seabirds capable of successfully flying out to sea when rehabilitated were not capable of regaining flight from the grounding site. This is not surprising given that both species nest on steep slopes in montane areas which gives them the necessary elevation to take off from their burrow sites and clear surrounding obstacles (A. F. Raine personal communication). In this study birds remained grounded even when the grounding site was clear of obstructions or there was a steady breeze, as has also been shown for fledglings of these and similar species grounded by light attraction each year (Podolsky et al. 1998, Rodríguez et al. 2017). One of the Newell's Shearwaters we found alive with a head injury had a very low body weight on intake, indicating it had been grounded and starving for some time. It succumbed to its injuries in care. Leaving these seabirds unassisted would almost certainly have resulted in death by dehydration, starvation, or predation (Rodríguez et al. 2017).

We found that searchability differed across regions, environment types, and powerlines heights, indicating that grounded bird searches on Kaua'i are subject to environmental bias. Our results showed that grounded seabirds could not show the true distribution or scale of seabird collision risk as nearly half of all observed collisions occurred at unsearchable powerlines. When monitoring powerlines at the landscape scale unsearchable terrain is likely common. In a boreal forest environment where trees are cleared under powerlines, Bevanger (1995) estimated that 10-30\% of their search corridor was unsearchable and, due mainly to the presence of water and tidal fluctuations, Saverno et al. (1996) estimated that $66-90 \%$ of their corridor could not be searched. On Kauai our searchability varied regionally from $60-98.3 \%$ unsearchable and overall, $80 \%$ of the area around powerlines could not be searched.

Powerlines constructed in the interior of the island away from the island's roads had very low to zero searchability and this was most extreme for powerlines closest to suitable seabird breeding habitat, powerlines in steep terrain, and the island's tallest powerlines which occurs where wires are strung from ridge to ridge over drainages. It is this correlation between searchability and the environmental factors that directly influence collision risk that explains the mechanism by which environmental bias on Kaua'i prevents ground searches from capturing the true geographic distribution and total impacts of powerlines. Using observed collisions, we estimated that at minimum 3,170 collisions occurred at the non-searchable powerlines monitored in this study. An additional 2,864 were estimated to have occurred at powerlines with such low searchability that it is highly improbable that birds would be grounded directly in the limited search space.

Three search studies have now been conducted on Kauai, two in the early 1990's (Cooper and Day 1998, Podolsky et al. 1998) and the present study. In the present study we consistently worked at all sections of the powerline grid and we walked the trails and visited the powerlines sections with the highest collision rates once a month for 9 years. Despite this effort, none of the ground searching conducted by any of the three studies was able to capture the fact that thousands of collisions were occurring at the interior powerlines in steep and unsearchable terrain.

As a consequence of ground searches indicating relatively low overall risk, virtually no powerline modifications were implemented to reduce seabird powerline collisions between the early 1990's when collision risk was first identified until midway 
Avian Conservation and Ecology 16(1): 15

http://www.ace-eco.org/vol16/iss1/art15/

through the present study. However, at the time of writing, several large-scale powerline modifications have recently been implemented. Due to the high cost of implementation, only a short section of high-risk powerlines have been undergrounded. Rather, initial modifications are focused on lowering wires out of seabird airspace by removing non-electrified wires (e.g., static wire) and rebuilding wire arrays horizontally rather than vertically. Effort to increase seabird detection and avoidance of the powerlines has focused on the attachment of bird diverters. Planting and or maintenance of fast-growing tall trees (at a safe distance from wires) can also promote birds flying higher than powerlines.

In the present study we confirmed that seabirds collide with powerlines in every region on Kaua'i, across all environment types studied, and at powerlines as low as 9 meters. Geographically, the scale of the seabird collision issue is island-wide as the powerlines with collisions encircle most of the suitable breeding habitat that remains for these seabirds. The wide range of habitats and powerline heights with confirmed collisions suggest that powerline collision risk is unlikely to be a Kaua'i specific problem. Based on our results, it should be assumed that collision risk exists on other Hawaiian Islands where Newell's Shearwaters or Hawaiian Petrels transit past powerlines, at least until proven otherwise. Collision risk should also be considered at other infrastructure that would be similarly hard to detect and avoid at night, such as guy wires on towers (Loss et al. 2012) and windmill blades (Barrios and Rodríguez 2004). Overall, similar risk likely exists for other species of petrels and shearwaters with similar life histories that breed inland of powerlines (Rodríguez et al. 2019) as well as other seabirds, particularly those that fly fast and have reduced maneuverability (Bevanger 1998) such as alcids. Our findings that search studies can miss thousands of collisions is of general concern for seabird conservation, but particularly for highly endangered species where powerline mortality for a small number of individuals is simultaneously unlikely to be detected and devastating to the population.

Identifying the threats faced by seabirds breeding on Kaua'i is critical to the conservation of both species because the majority of the worlds remaining Newell's Shearwaters along with significant proportions of the Hawaiian Petrel population breed on this single island (Cooper and Day 1998, Ainley et al. 2001, Raine et al. 2017). We have identified that powerline collisions are an island-wide issue on Kauai and estimate that thousands of collisions are occurring at just $3 \%$ of the total powerlines by length. Prior to the dramatic population declines of 78 and $94 \%$ for the Hawaiian Petrel and Newell's Shearwater respectively (Raine et al. 2017), there was considerably more seabirds transiting past the same powerlines monitored in the present study, which undoubtedly means collision rates were significantly higher in past decades. The available information clearly indicates that powerline collisions are the most significant anthropogenic conservation threat to the remaining populations of both endangered seabird species and are clearly a critical factor in their population declines. The next steps in this research will be to quantify total collisions and grounding rates at the island scale using methods that can quantify collisions in the non-searchable areas of the island and test the collision reduction efficacy of powerline modifications.
Responses to this article can be read online at: https://www.ace-eco.org/issues/responses.php/1841

\section{Acknowledgments:}

This work was undertaken through the Kaua'i Endangered Seabird Recovery Project (KESRP), which is a joint project of the Department of Land and Natural Resources, Division of Forestry and Wildife (DOFAW), and the Pacific Co-operative Studies Unit (PCSU) of the Research Corporation of the University of Hawaii. We would like to thank all the KESRP field technicians who have worked long nocturnal hours over the years to collect the data. We would like to thank Jeff Troy for providing us with access to the suitable breeding habitat GIS layers for both seabird species. We would like to thank staff from both PCSU and DOFAW for their continued support for this work. From PCSU we appreciate the support of David Duffy, Linda Hara, Dana Fukata, Michelle Miyata, Chin Lee Nicolaides, and Nicholas Joly. From DOFAW we appreciate the support of Sheri Mann, Afsheen Siddiqi, David Smith, Kate Cullison, Thomas Ka'iakapu, and Jason Omick. Lastly, we would like to thank Stephen Rossiter and the reviewers for providing helpful comments. Funding for this work was provided by the Kaua'i Island Utility Cooperative through their Short-term Habitat Conservation Plan.

\section{LITERATURE CITED}

Ainley, D. G., R. Podolsky, L. Deforest, G. Spencer, and N. Nur. 2001. The status and population trends of the Newell's Shearwater on Kaua'i: insights from modeling. Studies in Avian Biology 22:108-123.

Ainley, D. G., T. C. Telfer, M. H. Reynolds, and A. F. Raine. 2019. Newell's Shearwater (Puffinus newelli), version 2.0. Page The Birds of North America. Cornell Lab of Ornithology, Ithaca, NY, USA. https://doi.org/10.2173/bna.towshe2.02

Barrientos, R., J. C. Alonso, C. Ponce, and C. Palacín. 2011. Metaanalysis of the effectiveness of marked wire in reducing avian collisions with power lines: wire marking to reduce bird collisions. Conservation Biology 25:893-903. https://doi.org/10.1111/ j.1523-1739.2011.01699.x

Barrientos, R., R. Martins, F. Ascensão, M. D’Amico, F. Moreira, and L. Borda de Agua. 2018. A review of searcher efficiency and carcass persistence in infrastructure-driven mortality assessment studies. Biological Conservation 222. https://doi.org/10.1016/j. biocon.2018.04.014

Barrios, L., and A. Rodríguez. 2004. Behavioural and environmental correlates of soaring-bird mortality at on-shore wind turbines. Journal of Applied Ecology 41:72-81. https://doi. org/10.1111/j.1365-2664.2004.00876.x

Bernardino, J., K. Bevanger, R. Barrientos, J. F. Dwyer, A. T. Marques, R. C. Martins, J. M. Shaw, J. P. Silva, and F. Moreira. 2018. Bird collisions with power lines: State of the art and priority areas for research. Biological Conservation 222:1-13. https://doi. org/10.1016/j.biocon.2018.02.029 
Bevanger, K. 1995. Estimates and population consequences of tetraonid mortality caused by collisions with high tension power lines in Norway. The Journal of Applied Ecology 32:745. https:// doi.org/10.2307/2404814

Bevanger, K. 1998. Biological and conservation aspects of bird mortality caused by electricity power lines: a review. Biological Conservation 86:67-76. https://doi.org/10.1016/S0006-3207(97) 00176-6

Cooper, B. A., and R. H. Day. 1998. Summer behavior and mortality of Dark-rumped Petrels and Newell's Shearwaters at power lines on Kauai. Colonial Waterbirds 21:11-19. https://doi. org/10.2307/1521726

Day, R. H., and B. A. Cooper. 1995. Patterns of movement of Dark-rumped Petrels and Newell's Shearwaters on Kauai. The Condor 97:1011-1027. https://doi.org/10.2307/1369540

Dwyer, J. F., A. K. Pandey, L. A. McHale, and R. E. Harness. 2019. Near-ultraviolet light reduced Sandhill Crane collisions with a power line by $98 \%$. The Condor 121:duz008. https://doi. org/10.1093/condor/duz008

Elvidge, C. D., M. Zhizhin, T. Ghosh, F.-C. Hsu, and J. Taneja. 2021. Annual Time Series of Global VIIRS Nighttime Lights Derived from Monthly Averages: 2012 to 2019. Remote Sensing 13:922. https://doi.org/10.3390/rs13050922

Ferrer, M., V. Morandini, R. Baumbusch, R. Muriel, M. De Lucas, and C. Calabuig. 2020. Efficacy of different types of "bird flight diverter" in reducing bird mortality due to collision with transmission power lines. Global Ecology and Conservation 23: e01130. https://doi.org/10.1016/j.gecco.2020.e01130

Janss, G. F. E., and M. Ferrer. 1997. Rate of bird collisions with power lines: effects of conductor-marking and static wiremarking.Journal of Field Ornithology 69:8-17.

Jenkins, A. R., J. J. Smallie, and M. Diamond. 2010. Avian collisions with power lines: a global review of causes and mitigation with a South African perspective. Bird Conservation International 20:263-278. https://doi.org/10.1017/S0959270910000122

Loss, S. R., T. Will, and P. P. Marra. 2012. Direct human-caused mortality of birds: improving quantification of magnitude and assessment of population impact. Frontiers in Ecology and the Environment 10:357-364. https://doi.org/10.1890/110251

Loss, S. R., T. Will, and P. P. Marra. 2014. Refining estimates of bird collision and electrocution mortality at power lines in the United States. PLOS ONE 9:e101565. https://doi.org/10.1371/ journal.pone. 0101565

Loss, S. R., T. Will, and P. P. Marra. 2015. Direct Mortality of Birds from Anthropogenic Causes. Annual Review of Ecology, Evolution, and Systematics 46:99-120. https://doi.org/10.1146/ annurev-ecolsys-112414-054133

Murphy, R. K., E. K. Mojica, J. F. Dwyer, M. M. McPherron, G. D. Wright, R. E. Harness, A. K. Pandey, and K. L. Serbousek. 2016. Crippling and Nocturnal Biases in a Study of Sandhill Crane (Grus canadensis) Collisions with a Transmission Line. Waterbirds 39:312-317. https://doi.org/10.1675/063.039.0312

Podolsky, R., D. G. Ainley, G. Spencer, L. Deforest, and N. Nur. 1998. Mortality of Newell's Shearwaters caused by collisions with urban structures on Kauai. Colonial Waterbirds 21:20-34. https:// doi.org/10.2307/1521727

Pyle, R.L., and P. Pyle. 2017. The Birds of the Hawaiian Islands: Occurrence, History, Distribution, and Status. B.P. Bishop Museum, Honolulu, HI, U.S.A. Version 2(1 January 2017). http:// hbs.bishopmuseum.org/birds/rlp-monograph

Raine, A., T. Anderson, M. Vynne, S. Driskill, H. Raine, and J. Adams. 2020. Post-release survival of fallout Newell's shearwater fledglings from a rescue and rehabilitation program on Kaua'i, Hawai'i. Endangered Species Research 43:39-50. https://doi. org/10.3354/esr01051

Raine, A. F., N. D. Holmes, M. Travers, B. A. Cooper, and R. H. Day. 2017. Declining population trends of Hawaiian Petrel and Newell's Shearwater on the island of Kaua'i, Hawaii, USA. The Condor 119:405-415. https://doi.org/10.1650/CONDOR-16-223.1

Rioux, S., J.-P. L. Savard, and A. A. Gerick. 2013. Avian mortalities due to transmission line collisions: a review of current estimates and field methods with an emphasis on applications to the Canadian electric network. Avian Conservation and Ecology 8(2):7. https://doi.org/10.5751/ACE-00614-080207

Rodríguez, A., J. M. Arcos, V. Bretagnolle, M. P. Dias, N. D. Holmes, M. Louzao, J. Provencher, A. F. Raine, F. Ramírez, B. Rodríguez, R. A. Ronconi, R. S. Taylor, E. Bonnaud, S. B. Borrelle, V. Cortés, S. Descamps, V. L. Friesen, M. Genovart, A. Hedd, P. Hodum, G. R. W. Humphries, M. Le Corre, C. Lebarbenchon, R. Martin, E. F. Melvin, W. A. Montevecchi, P. Pinet, I. L. Pollet, R. Ramos, J. C. Russell, P. G. Ryan, A. SanzAguilar, D. R. Spatz, M. Travers, S. C. Votier, R. M. Wanless, E. Woehler, and A. Chiaradia. 2019. Future Directions in Conservation Research on Petrels and Shearwaters. Frontiers in Marine Science 6. https://doi.org/10.3389/fmars.2019.00094

Rodríguez, A., N. D. Holmes, P. G. Ryan, K.-J. Wilson, L. Faulquier, Y. Murillo, A. F. Raine, J. F. Penniman, V. Neves, B. Rodríguez, J. J. Negro, A. Chiaradia, P. Dann, T. Anderson, B. Metzger, M. Shirai, L. Deppe, J. Wheeler, P. Hodum, C. Gouveia, V. Carmo, G. P. Carreira, L. Delgado-Alburqueque, C. GuerraCorrea, F.-X. Couzi, M. Travers, and M. L. Corre. 2017. Seabird mortality induced by land-based artificial lights: Seabird Mortality and Artificial Lights. Conservation Biology 31:986-1001. https://doi.org/10.1111/cobi.12900

Saverno, A. J., L. A. Saverno, R. Boettcher, and S. M. Haig. 1996. Avian behavior and mortality at power lines in coastal South Carolina. Wildlife Society Bulletin 24:636-648.

Troy, J. R., N. D. Holmes, J. A. Veech, A. F. Raine, and M. C. Green. 2014. Habitat suitability modeling for the Newell's Shearwater on Kauai. Journal of Fish and Wildlife Management 5:315-329. https://doi.org/10.3996/112013-JFWM-074

Troy, J. R., N. D. Holmes, J. A. Veech, A. F. Raine, and M. C. Green. 2017. Habitat suitability modeling for the endangered Hawaiian Petrel on Kauai and analysis of predicted habitat overlap with the Newell's Shearwater. Global Ecology and Conservation 12:131-143. https://doi.org/10.1016/j.gecco.2017.10.002

Weimerskirch, H., P. Pinet, J. Dubos, S. Andres, J. Tourmetz, C. Caumes, S. Caceres, M. Riethmuller, and M. L. Corre. 2019. 
Wettability of juvenile plumage as a major cause of mortality threatens endangered Barau's petrel. Journal of Avian Biology 50 (1). https://doi.org/10.1111/jav.02016

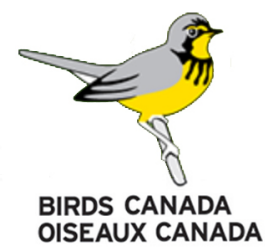

